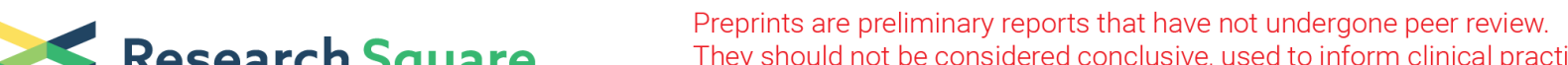 $\begin{array}{ll}\text { Research Square } & \text { They should not be considered conclusive, used to inform clinical practice, } \\ \text { or referenced by the media as validated information. }\end{array}$
}

\section{Fairness in Household Financial Contribution to the Healthcare System; the Evidence of Iran from 2008 to 2018}

\section{Ali Darvishi}

Tehran University of Medical Sciences

Mostafa Amini-Rarani

Isfahan University of Medical Sciences

Mohammad Hossein Mehrolhassani

Kerman University of Medical Sciences

Vahid Yazdi-Feyzabadi ( $\boldsymbol{D}$ v_yazdi@kmu.ac.ir)

Institute for Futures Studies in Health, Kerman University of Medical Sciences https://orcid.org/00000002-8009-470X

\section{Research note}

Keywords: Fair Financial Contribution Index (FFCl), Equity in Health, Iran's health transformation programm (HTP)

Posted Date: January 28th, 2021

DOI: https://doi.org/10.21203/rs.3.rs-154691/v1

License: (1) This work is licensed under a Creative Commons Attribution 4.0 International License. Read Full License 


\section{Abstract}

Objective: The achievement of equity in health leads to health gains and financial risk protection and this issue was one of the important goals of Iran's health transformation programm (HTP). The present study aimed to how the HTP achieved its objectives in terms of fair financial protection by assessing the Fair Financial Contribution Index (FFCl) in various households of urban and rural areas before (2008-2013) and after (2014-2018) the implementation of the HTP.

Results: According to the sample analyzed, 207,980 and 212,249 of households lived in urban and rural areas, respectively. The worst fair contributions to health expenditure in urban $(\mathrm{FFCl}=0.684)$ and rural areas ( $\mathrm{FFCl}=0.530)$ were occurred in 2010 and 2009, respectively. Otherwise, the best fair contributions for urban areas $(\mathrm{FFCl}=0.858)$ and rural areas $(\mathrm{FFCl}=0.836)$ were made in 2011. Before the HTP implementation was began (between 2008 and 2013), FFCl witnessed minor changes from 0.834 in 2008 to 0.833 in 2013. Following the HTP implementation, the $\mathrm{FFCl}$ values in urban and rural population declined (worsened) from 0.842 to 0.836 and 0.816 to 0.809 , respectively. Overall, $\mathrm{FFCl}$ has been improved during years after the implementation of HTP. Such that, the improvement was shown more in rural areas.

\section{Introduction}

Equity in utilization and resource distribution is an essential intermediate objective of health financing policy [1]. The achievement of this objective leads to health gains and financial risk protection, especially for those in need. Since 2000, the WHO has drawn attention to ensure equitable (or fair) financing for health care, highlighting that health systems are not just about improving health status. However, also improving fairness through health system financing and delivery has a broader social value [2]. In the 2010 World Health Report, the fair financial contribution was considered to be the main criterion for achieving universal health coverage. [3].

Generally, different methods have been used to finance health systems, including tax-based insurance, social insurance, private insurance, and Out-of-Pocket (OOP) payment [4]. From the viewpoint of both risk protection and equity, OOP payments is considered to be the worst possible form of health financing [5, 6]. Evidence shows that the high share of OOP payments for health services is a sign of inadequate social health coverage and can lead to economic hardship, particularly in low-and middle-income countries [7, 8]. OOP imposes the most significant burden on the poor and carries a high risk of falling households into poverty by imposing Catastrophic Health Expenditure (CHE) [9]. To this end, WHO has more than ever emphasized the CHE and the Fair Financial Contribution Index (FFCl) as equity indicators for household financial contributions to health systems $[10,11]$ and recommended the universal health coverage strategy with the aim of ensuring that all people have access to the required health services without any financial difficulties at the time of receiving services. 
In Iran, given the requirements of the National Five-Year Development Plans to address high OOP rates, i.e., $52.1 \%$ of total health expenditure [12], the increased contribution of the government in providing the funds for public health expenses and appropriate allocation of public resources in the health sector are of great importance. Accordingly, in May 2014, the Ministry of Health and Medical Education (MoHME) of Iran implemented a comprehensive health system transformation package called the Health Transformation Plan (HTP) [13]. The reduction in the percentage of OOP payments and the reduction in the percentage of households facing CHE were identified as top priorities in HTP content.

Even though various indices such as the Kakwani index, Gini coefficient, $\mathrm{CHE}$, and the impoverishment index [14] can be assessed for the performance of the health system, the WHO emphasizes the $\mathrm{FFCl}$ as an essential measure $[11,15]$. Fairness in healthcare financing is assessed by the level of inequality in the payment of health care between households of unequal Capacity to Pay (CtP) [16].

Overall, equitable financing is a crucial objective of healthcare systems and healthcare financial risk protection, recommended to be measured on a continuous and periodic basis every $2-5$ years $[5,17]$.

The present study aims to how the HTP achieved its objectives in terms of fair financial protection by assessing $\mathrm{FFCl}$ in various households of urban and rural areas before (2008-2013) and after (20142018) the implementation of the HTP.

\section{Methods}

The present study is a retrospective descriptive study that was conducted using annual national repeated cross-sectional surveys on households' income and expenditure from 2008 to 2018 in Iran.

Iran's household expenditure and income survey plan have been implemented in rural areas since 1963 and urban areas since 1968 by Iran Statistical Center (ISC). In addition to household expenditure, income information has also been collected since 1974 and has been given annually to date. In this plan, information related to the average expenditures and income of an urban and rural household in the country is provided annually. Data obtained from this annual survey are collected using a questionnaire for about 38,000 Iranian households that have been sampled and entered into the survey in a step-by-step manner. The questionnaire includes three sections, including socio-economic characteristics of the household, expenses (household food and non-food expenses), and household income. The pillars studied in this survey are the educational status of the household, household assets, access to basic facilities and public goods and household expenses in various sectors such as Health [18].

The sample size of the data used in the study is presented in the form of Table 1 separately for each year and the urban and rural population.

Table 1: Sample Size in Study Years 


\begin{tabular}{|cccc|}
\hline Year & Urban & Rural & Total \\
\hline 2018 & 19382 & 19708 & 39090 \\
\hline 2017 & 18666 & 18204 & 36870 \\
\hline 2016 & 18702 & 19585 & 38287 \\
\hline $\mathbf{2 0 1 5}$ & 18728 & 19787 & 38515 \\
\hline $\mathbf{2 0 1 4}$ & 18536 & 19658 & 38194 \\
\hline $\mathbf{2 0 1 3}$ & 18881 & 19437 & 38318 \\
\hline $\mathbf{2 0 1 2}$ & 18886 & 19391 & 38227 \\
\hline $\mathbf{2 0 1 1}$ & 18872 & 19382 & 38254 \\
\hline $\mathbf{2 0 1 0}$ & 18809 & 19340 & 38149 \\
\hline $\mathbf{2 0 0 9}$ & 18205 & 19207 & 37412 \\
\hline $\mathbf{2 0 0 8}$ & 20313 & 18550 & 38,863 \\
\hline Total & $\mathbf{2 0 7 9 8 0}$ & $\mathbf{2 1 2 2 4 9}$ & $\mathbf{4 2 0 1 7 9}$ \\
\hline
\end{tabular}

In order to calculate and compare households' fair financial contribution in health expenditures, the distribution of household financial contributions among them is summarized using an index called the $\mathrm{FFCl}$. This index puts much weight on households that spend a high proportion of their income on health. $\mathrm{FFCl}$ generally reflects inequality in the financial contribution of households in health, although it reflects explicitly households that face catastrophic health expenditures. The mathematical cube-root is used to place more weight on households in the distribution sequence. In this study, the following equation has been used to calculate the values of health expenditures FFCl.

$$
F F C I=1-\sqrt[3]{\frac{\sum_{h=1}^{n} w_{h} / o o p c t p_{h}-o o p c t p_{0} / 3}{\sum w_{h}}}
$$

Where $w_{\mathrm{h}}$ represents households sampling weights, oopctp ${ }_{h}$ represents the ratio of OOPs to the household's CtP for health expenditures, which shows the financial burden borne for health services. The steps and details of the calculation of CtP are presented in another study by the researchers $[19,20]$. Also, the value of $o o p_{0}$ In the above Formula is obtained from the following equation: 


\section{$\operatorname{oop}_{0}=\frac{\sum w_{h} \times o o p_{h}}{\sum w \times c t p_{h}}$}

$\mathrm{FFCl}$ calculations were performed for six years before the HTP implementation and five years after it, and its trend in these years was reviewed and analyzed. Excel 2016 and Stata 14 software were used to prepare the data and analyze the results.

\section{Results}

The total sample sizes for urban and rural areas from 2008 to 2018 are shown in Table 1. According to the sample analyzed, 207,980 and 212,249 of households lived in urban and rural areas, respectively.

The FFCl results before and after the HTP in rural areas, urban areas, and the total population are shown in Table 2. The worst fair contributions to health expenditure in urban $(\mathrm{FFCl}=0.684)$ and rural areas $(\mathrm{FFCl}$ $=0.530$ ) were occurred in 2010 and 2009, respectively. Otherwise, the best fair contributions for urban areas $(\mathrm{FFCl}=0.858)$ and rural areas $(\mathrm{FFCl}=0.836)$ were made in 2011. During 2008 and 2009, the values of $\mathrm{FFCl}$ for urban, rural and total population were reduced and worsened from 0.842 to $0,750,0.821$ to 0.530 , and 0.834 to 0.657 , respectively. In comparison, the $\mathrm{FFCl}$ values were increased in 2010 , except for urban areas. Before the HTP implementation was began (between 2008 and 2013), FFCl witnessed minor changes from 0.834 in 2008 to 0.833 in 2013. Following the HTP implementation (between 2014 and 2018), the FFCl values in urban, rural, and the total population declined (worsened) from 0.842 to 0.836 , 0.816 to 0.809 , and 0.833 to 0.829 , respectively. Consequently, during the five years of HTP implementation, the FFCs have slightly worsened by $0.71 \%, 0.85 \%$, and $0.48 \%$ in urban areas, rural areas, and total population, respectively.

Generally and on average, fairness in health expenditure contribution has experienced $4.34 \%, 6.37 \%$ and $5.85 \%$ improvements following the HTP in urban areas, rural areas and total population of Iran (Table 2). 
Table 2

FFCI Values in Urban and Rural Iranian Households and Mean Value before and after the HTP

\begin{tabular}{|lllll|}
\hline & Year & Urban & Rural & Total \\
\hline Before the HTP & 2008 & 0.842 & 0.821 & 0.834 \\
\hline 2009 & 0.75 & 0.53 & 0.657 \\
\hline 2010 & 0.684 & 0.78 & 0.703 \\
\hline 2011 & 0.858 & 0.836 & 0.85 \\
\hline 2012 & 0.855 & 0.828 & 0.846 \\
\hline 2013 & 0.841 & 0.817 & 0.833 \\
\hline After the HTP & 0.805 & 0.769 & 0.787 \\
\hline 2014 & 0.842 & 0.816 & 0.833 \\
\hline 2015 & 0.842 & 0.822 & 0.835 \\
\hline 2016 & 0.839 & 0.823 & 0.833 \\
\hline 2017 & 0.84 & 0.821 & 0.834 \\
\hline 2018 & 0.836 & 0.809 & 0.829 \\
\hline Mean & 0.84 & 0.818 & 0.833 \\
\hline $\begin{array}{l}\text { Percentage of changes(Based on after HTP) } \\
\text { Mean before }\end{array}$ & $\begin{array}{l}4.34 \% \\
\text { improvement }\end{array}$ & $\begin{array}{l}6.37 \% \\
\text { improvement }\end{array}$ & $\begin{array}{l}5.85 \% \\
\text { improvement }\end{array}$ \\
\hline
\end{tabular}

Figure 1 depicts changes in FFCls in the contribution of Iranian households to health expenditure for the years 2008 to 2018. Throughout this period, the best and the worst indices are belonging to urban areas in 2011 and rural areas in 2009, respectively. The rise of the $\mathrm{FFCl}$ value in the first year of HTP implementation in 2014 almost stopped the declining trend that started in 2013. After a slight rise in 2015 , the overall FFCl stayed almost constant in 2015-2017 and then decreased in 2018. The pattern of improvement of the $\mathrm{FFCl}$ for residence in rural areas occurred dramatically after the introduction of the HTP up to 2016 , but undesirably declining in the last two years. In contrast, the FFCls for urban areas underwent small improvements following the HTP.

\section{Discussion}

The $\mathrm{FFCl}$ is one measure that can help policymakers recognize the flaws in the financial protection mechanisms embedded in the health financing system. According to our 11-year analysis, it is clear that financial contributions in Iranian households on average were $21 \%$ and $18 \%$ away from achieving complete fairness in rural and urban areas, respectively. As far as HTP is concerned, intending to improve the distribution of health expenditure across various socio-economic groups, the results of this study 
showed that more fair financial contributions had been made after the HTP, particularly in rural areas. Despite the decline in $\mathrm{FFCl}$ in 2018, the financing contributions in health payments were generally improved at the country level following five years after the HTP. In addition, FFCls have shown higher inequalities in rural areas compared to urban areas both before and after the HTP.

Previous studies from different regions of Iran have been reported $\mathrm{FFCl}$ values ranging from 0.83 in a national study in 2016 [14] to 0.6 in a study conducted in Shiraz province in 2012 [4] or 0.56 in Kermanshah province in 2005 [21]. In 2012, Raghfar et al. reported FFCl levels with slight fluctuations in 1984-2010. The FFCl values were 0.76 and 0.79 in the rural and urban sectors in 1984, respectively. In 2010, it was 0.79 in both the rural and urban sectors [22]. In their study, Fazaeli et al. showed that the FFCl decreased from 0.841 in 2003 to 0.827 in 2010, and this trend showed a decline in the fair financial contribution to health expenditure. [23]. The results of the study conducted by Mousavi et al. in 2018 also showed that $\mathrm{FFCl}$ of Iranian households ranged from 0.83 in 2009 to 0.91 in 2014 and experienced minor fluctuations from 1989-2014. In this study, the lowest $\mathrm{FFCl}$ value was measured in 2009 , in line with the current study [24].

Results on the trend of FFCl after HTP compared to before its implementation has shown that improvements have occurred, and average $\mathrm{FFCl}$ values are closer to the equity level. However, by examining this index from year to year, it is clear that the numerical values of the index did not change significantly in 2018 compared to 2013 and were almost constant. So, consistent with the Kheibari et al.' study [14] could be stated that fair contribution to financing improved after the HTP but less than that expected. The reasons behind the small improvements in the FFCl could be explained as follows. First, the HTP focuses only on inpatient services delivered in hospitals affiliated with medical universities under the sponsorships of the MoHME. Accordingly, outpatient and inpatient services provided in other hospitals and the private sector, which have a high proportion of services almost not considered being part of the HTP. Second, despite the existence of clinical guidelines for various medical and health services, but in practice, health and medical services are not provided based on these guidelines, which may increase the cost of treatment and increase OOP payments. Third new relative value-based scales and the relative increase of tariffs in various medical specialties and subspecialties in this plan, although the percentage of OOP in the inpatient department has decreased, the absolute amount of OOP payments has practically increased.

As part of the HTP, the relative value of health care and services has been increased to motivate healthcare providers to deliver high-quality services [25] according to the new relative value book (2016 edition) [26]. As a result, new medical tariffs ascended the absolute amounts of OOP payments irrespective of reduction in payment for inpatient services. Forth, the demand for health services delivered in the public sectors has been stimulated by the HTP and, due to human, financial, and equipment constraints, many people in the public sector (such as public hospitals) have needlessly been referred to the private sector. This has doubled the financial burden on households.

\section{Conclusion}


We concluded that $\mathrm{FFCl}$ has been improved during years after the iimplementation of HTP than before ones. Overall, the improvement was shown more in rural areas than urban ones. Another conclusion drawn from the present study is that there is still a defference between level of $\mathrm{FFCl}$ and the targeted level (as determined 90\%) in national development plans. This necessitates the strengthen actions and interventions to reduce and achieve to desired level recommended by the WHO for the OOP spending (Up to $15-20 \%)$.

\section{Limitations}

This study had some limitations which should be addressed. First, an inherent drawback of the FFCl is that it represents both vertical and horizontal equity, without distinguishing between them, though, as Wagstaff (2002) declares [27], the two suggest very different policy implications. Another limitation is related to this issue that this index cannot distinguish between progressive and regressive health financing.

\section{Abbreviations}

$\mathrm{FFCl}$

Fair Financial Contribution Index

HTP

Health Transformation Programm

OOP

Out-of-Pocket

CHE

Catastrophic Health Expenditure

CtP

Capacity to Pay

\section{Declarations}

\section{Ethics approval and consent to participate}

Present study was approved by ethical committee of Kerman University of Medical Sciences. The Ethic approval Cod is IR.KMU.REC.1398.039. Consent to participation not applicable in present study.

\section{Consent for publication}

Not applicable

\section{Availability of data and material}


All data obtained during this study is included in this article. The datasets used and/or analysed during the current study are available from the corresponding author on reasonable request.

\section{Competing interests}

The authors have declared that no competing interests exist

\section{Funding}

No funding to declare

\section{Author's contributions}

VYF designed the study. AD analyzed the data. MAR, MHM and VYF drafted the manuscript. All authors read and approved the final manuscript.

\section{Acknowledgements}

The authors would like to thank Iran Statistics Center (ISC) for providing the national crude data in order to conduct this study.

\section{Authors' information}

${ }^{1}$ Ph.D Candidate in Health Economics, Department of Health Management and Economics, School of Public Health, Tehran University of Medical Sciences, Tehran, Iran. ${ }^{2}$ Ph.D in Health Policy (Assistant professor),Social Determinants of Health Research Center, Isfahan University of Medical Sciences, Isfahan, Iran. ${ }^{3}$ Ph.D in Health Services Management (Associate professor), Social Determinants of Health Research Center, Institute for Futures Studies in Health, Kerman University of Medical Sciences, Kerman, Iran. ${ }^{4}$ Ph.D in Health Policy (Assistant professor), Health Services Management Research Center, Institute for Futures Studies in Health, Kerman University of Medical Sciences, Kerman, Iran.

\section{References}

1. Zandam $\mathrm{HU}$. and Juni $\mathrm{MH}$, Health economics evaluation in health financing policy. International Journal of Public Health and Clinical Sciences, 2015. 2(3): 8-22.

2. Mclntyre D. WHR 2000 to WHR 2010: what progress in health care financing? Health policy and planning, 2010. 25(5): 349-351. 
3. World Health Organization. World health report 2010: Health systems financing: the path to universal coverage. 2010.

4. Kavosi Z., Keshtkaran A., Hayati R., Ravangard R., Khammarnia., M. Household financial contribution to the health System in Shiraz, Iran in 2012. International journal of health policy and management, 2014. 3(5): 243.

5. Khammarnia, M., Setoodehzadeh F., Ansari-Moghaddam A., Barfar E., Zanganeh M., Peyvand M. Household financial contribution to the health system after Iran's Health Transformation Plan. Rural and remote health, 2020. 20(1): 5495-5495.

6. Roberts M., Hsiao W., Berman P., Reich M. Getting health reform right: a guide to improving performance and equity. 2003: Oxford university press.

7. Mclntyre D., Thiede M., Dahlgren G., Whitehead M. What are the economic consequences for households of illness and of paying for health care in low-and middle-income country contexts? Social science \& medicine, 2006. 62(4): 858-865.

8. Van Doorslaer E, O'Donnell O, Rannan-Eliya RP, Somanathan A., Adhikari SR., Garg CC., et al. Effect of payments for health care on poverty estimates in 11 countries in Asia: an analysis of household survey data. The lancet, 2006. 368(9544): 1357-1364.

9. Yazdi-Feyzabadi V., Mehrolhassani MH, Darvishi A. Measuring catastrophic health expenditures and its inequality: Evidence from Iran's health transformation program. Health policy and planning, 2019. 34(4): 316-325.

10. Murray CJ., Xu K, Klavus J. Assessing the distribution of household financial contributions to the health system: concepts and empirical application. Health systems performance assessment: debates, methods and empiricism. Geneva: World Health Organization, 2003.

11. World Health Organization. The world health report 2000: health systems: improving performance. 2000: World Health Organization.

12. Mousavi SM. and J. Sadeghifar, Universal health coverage in Iran. The Lancet Global Health, 2016. 4(5): p. e305-e306.

13. Moradi-Lakeh M.,Vosoogh-Moghaddam A. Health sector evolution plan in Iran; equity and sustainability concerns. International journal of health policy and management, 2015. 4(10): 637.

14. Kheibari MJ., Esmaeili R., and Kazemian M. Impacts of Health Reform Plan in Iran on Health Payments Distributions and Catastrophic Expenditure. Iranian Journal of Public Health, 2019. 48(10): 1861.

15. World Health Organization. Distribution of health payments and catastrophic expenditures methodology. 2005, World Health Organization.

16. Yu CP., Whynes DK., and Sach TH. Equity in health care financing: The case of Malaysia. International journal for equity in health, 2008. 7(1): p. 15.

17. Saksena P., Hsu J., and Evans D.B. Financial risk protection and universal health coverage: evidence and measurement challenges. PLoS Med, 2014. 11(9): p. e1001701. 
18. Iranian Statistics Center. The questionnaire of Households Income and Expenditure Survey. 2020, Iranian Statistics Center. Available from: http://www.amar.org.ir/Default.aspx? tabid=1136\&agentType=ViewType\&PropertyTypelD=257. Last accessed on 15 June 2020.

19. Yazdi-Feyzabadi V., Bahrampour M., Rashidian A., Haghdoost AA., Abolhallaje M., Najafi B., et al. Incidence and intensity of catastrophic health expenditures in Iranian provinces; 2008-2014. Iranian Journal of Epidemiology, 2017. 12: 40-54. (Persian)

20. Yazdi-Feyzabadi V., Akbari Javar M., Mehrolhassani MH. Prevalence and intensity of catastrophic health care expenditures in Iran from 2008 to 2015: a study on Iranian household income and expenditure survey. International journal for equity in health, 2018. 17(44): 1-13.

21. Razavi S., Hassanzadeh A., and Basmenji K. Fairness in financial contribution in the health system. Tehran: Andishmand publication. 2005. (Persian)

22. Raghfar H., Atrkar RS., and Atefi M. Measurement of the fair financial contribution index and catastrophic expenditures in different regions of Iran, 1984-2010. 2013.

23. Fazaeli AA., Seyedin H., Vosoogh Moghaddam A., Delavari A., Salimzadeh H., Varmazyar H., Fazaeli AA. Fairness of financial contribution in Iranian health system: Trend analysis of national household income and expenditure, 2003-2010. Global journal of health science, 2015. 7(5): 260.

24. Mousavi MH., Raghfar H., Fazel Z. Analysis equity in financing of household's health in development programs of Iran. Hakim Research Journal, 2018. 21(1): 1-12.

25. Mosadeghrad AM., Mirzaei N., Afshari M., Darrudi A. The impact of health transformation plan on health services fees: brief report. Tehran University Medical Journal TUMS Publications, 2018. 76(4): 277-282.

26. Ministry of Health and Medical Education of Iran. The relative value of health care services in the Islamic Republic of Iran. Treatment department of Ministry of Health and Medical Education, 2015.

27. Wagstaff A. Reflections on and alternatives to WHO's fairness of financial contribution index. Health Economics, 2002. 11(2): 103-115.

\section{Figures}




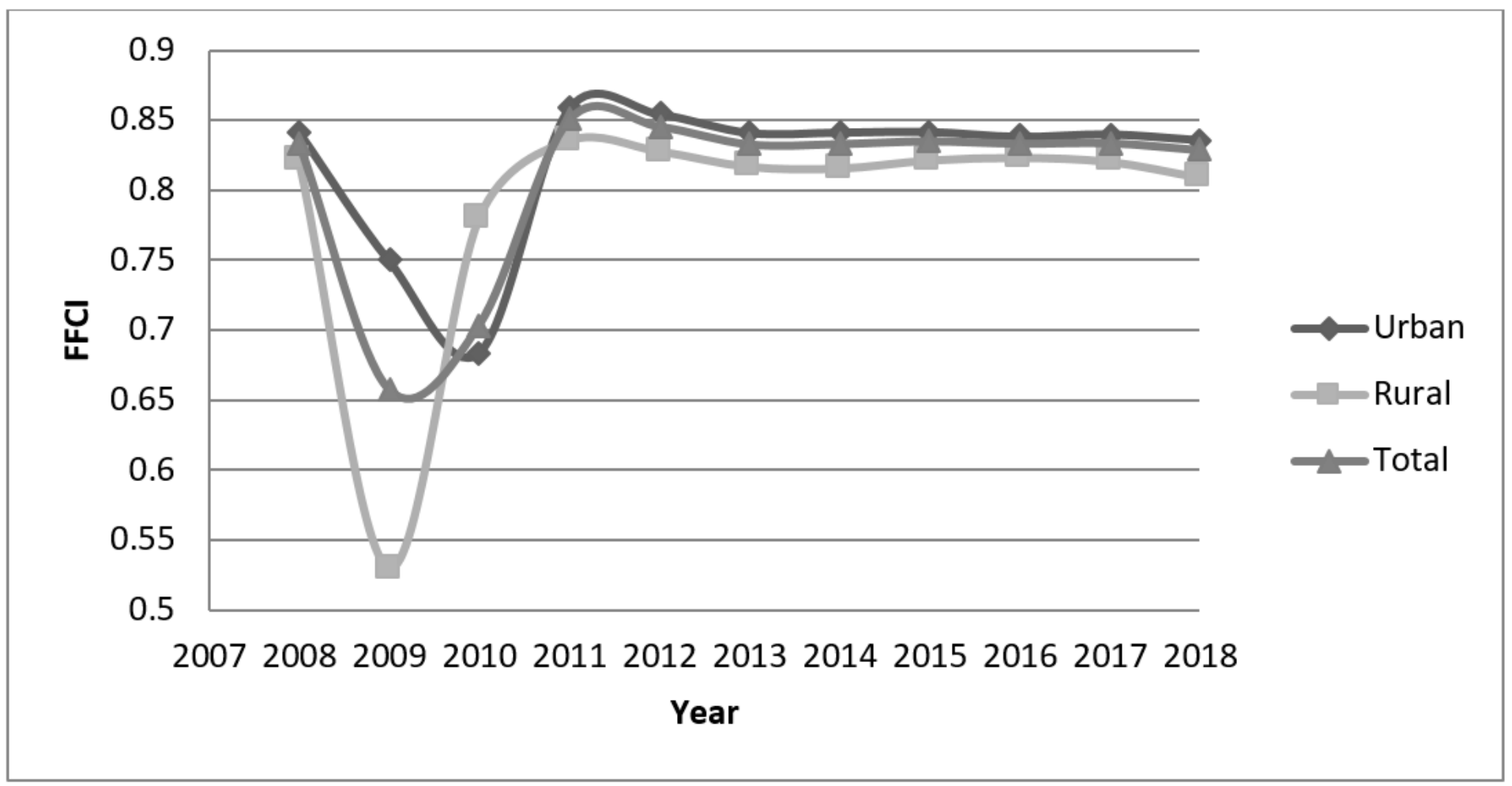

Figure 1

Fair financial contribution to health expenditure in Iran (2008-2018) 